\title{
Non-penetrating glaucoma surgery for advanced open-angle glaucoma
}

\author{
David Wong ${ }^{1}$ \\ Received: 21 May 2018 / Accepted: 29 May 2018 / Published online: 18 June 2018 \\ (C) Springer-Verlag GmbH Germany, part of Springer Nature 2018
}

NICE guidelines (November 2017) recommend that patients with advanced chronic open-angle glaucoma should be offered surgery with augmentation as indicated. The guidelines stress the need to offer information on the risks and benefits of surgery [1]. Such information depends of course on the nature of surgery. Eldaly et al. undertook a Cochrane Database Systematic Reviews in 2014 comparing non-penetrating filtration surgery with trabeculectomy for open-angle glaucoma [2]. The authors concluded that there was some limited evidence that control of IOP is better with trabeculectomy than viscocanalostomy. Therefore, some might think that advanced glaucoma should only be treated with penetrating glaucoma surgery. On the other hand, systematic review and meta-analysis also showed that trabeculectomy was associated with a higher incidence of complications compared to nonpenetrating surgery [3]. Such complications include hypotony, choroidal effusion, cataract, and flat or shallow anterior chamber and importantly sudden and further visual loss or "wipe out." What evidence do we have of the safety and efficacy of non-penetrating surgery for advanced open-angle glaucoma?

In this issue, we have two complementary papers on nonpenetrating glaucoma surgery for advanced glaucoma. Tsagkataki et al. reported on viscocanalostomy and phacoviscocanalostomy for advanced glaucoma. Leleu et la reported on the central $10^{\circ}$ visual field change following nonpenetrating deep sclerectomy in severe and end-stage glaucoma. The first study from Liverpool was remarkable in that it involved 133 patients, probably the largest number of patients with the longest follow-up of up to 3 years. The authors found that viscocanalostomy and phacoviscocanalostomy were able

David Wong

shdwong@gmail.com

1 Department of Eye and Visual Science, University of Liverpool, Liverpool, England to achieve an IOP $\leq 21 \mathrm{mmHg}$ in $80 \%$ (3 years) to $95 \%$ (1 year) patients with a 35-39\% drop in IOP from baseline with a good safety profile. The second study showed that 28 (82\%) eyes had an IOP < $21 \mathrm{mmHg}$ and $19(56 \%)$ an IOP $<$ $16 \mathrm{mmHg}$. The MD 10-2 remained stable ( -19.87 .4 to -19.4 $8.1 \mathrm{~dB}$, non-significant improvement of $+0.4 \mathrm{~dB}, P=0.1)$. As with most series, the deep sclerectomy involved augmentation with mitomycin in all cases, collagen implant in some and in the postoperative period additional measures such as goniopuncture, needling, and iridoplasty. The authors focused on visual complications and stressed that there were no "wipe out" of the visual field, which had been a main concern for penetrating glaucoma surgery in advanced glaucoma [4-6].

Potentially, these two papers might influence the way we treat glaucoma cases with severe visual field loss, that is with earlier surgical rather than medical intervention, with non-penetrating rather than with trabeculectomies.

\section{References}

1. NICE Guideline NG81 (2017) Glaucoma: diagnosis and management. https://www.nice.org.uk/guidance/ng81. Accessed 18 May 2018

2. Eldaly MA, Bunce C, N A, MM K (2014) Non-penetrating filtration surgery versus trabeculectomy for open angle glaucoma. Cochrane Database Syst Rev (2): https://doi.org/10.1002/14651858. CD007059.pub2

3. Rulli E, Biagioli E, Riva I, Gambirasio G, De Simone I, Floriani I, Quaranta L (2013) Efficacy and safety of trabeculectomy vs nonpenetrating surgical procedures: a systematic review and metaanalysis. JAMA Ophthalmol 131:1573-1582

4. Aggarwal SP, Hendeles S (1986) Risk of sudden visual loss following trabeculectomy in advanced primary open angle glaucoma. Br J Ophthalmol 70(2):97-99

5. Costa VP, Smith M, Spaeth GL, Gandham S, Markovitz B (1993) Loss of visual acuity after trabeculectomy. Ophthalmology 100(5): 599-612

6. Topouzis F, Tranos P, Koskosas A, Pappas T, Anastasopoulos E, Dimitrakos S et al (2005) Risk of sudden visual loss following filtration surgery in end-stage glaucoma. Am J Ophthalmol 140(4): 661-666 